\title{
Environment and ryegrass genetics - multisite trial of advanced breeding populations
}

\author{
H.S. EASTON ${ }^{1}$, M.Z.Z. JAHUFER ${ }^{1}$, C. FLAY ${ }^{1}$, J. SCHMIDT ${ }^{1}$, M.P. ROLSTON ${ }^{2}$, \\ J.A.K. TRETHEWEY ${ }^{2}$, D.L. RYAN ${ }^{3}$ and M.J. FAVILLE ${ }^{1}$ \\ ${ }^{1}$ AgResearch, Grasslands Research Centre, Private Bag 11008, Palmerston North 4442 \\ ${ }^{2}$ AgResearch, Lincoln Research Centre, Private Bag 4749, Christchurch 8140 \\ ${ }^{3}$ AgResearch, Ruakura Research Centre, Private Bag 3123, Hamilton 3240
}

sydney.easton@agresearch.co.nz

\begin{abstract}
Developing a genomic selection (GS) strategy for ryegrass requires field data for training GS models and to gain insight into how ryegrass agronomic performance varies, within and among populations and across locations. Families from five perennial ryegrass breeding populations are being evaluated in eight trials in Northland, Waikato, Hawke's Bay, Manawatu and Canterbury to establish a data set for development of a genomic selection model. Statistically robust variances are evident among families within populations, both for visual scoring of herbage bulk and dry matter measurements. Multi-trial analysis of data showed significant $(\mathrm{P}<0.001)$ differences among families, robust across trials, even though interaction with trial was also significant in some seasons. Patterns are also evident comparing trials, with relative performance of families being similar for some pairs of trials, but radically different for others. Evidence for specific response of families to severe summer management was not conclusive.
\end{abstract}

Keywords: genomic selection, ryegrass, genotype by environment interaction

\section{Introduction}

The historic rate of genetic gain for annual herbage yield in perennial ryegrass (PRG; Lolium perenne L.) has been relatively modest, estimated at $3-6 \%$ per decade in different parts of the world (Brummer \& Casler 2014; Easton et al. 2002). By contrast, the rate of genetic improvement for grain yield in major cereal crops such as maize (Smith et al. 2014) and wheat (Graybosch et al. 2014) has exceeded 10\% per decade. Increasing the rate of genetic gain for major traits in PRG, and other forages, is a priority (Chapman et al. 2012; Williams et al. 2007) for meeting the nutritional demands of high genetic merit livestock.

Genomic selection (GS) is a breeding strategy in which the effects of dense, genome-wide DNA markers on plant traits are first established in a training population and then used to predict genetic value of selection candidates that have been DNA-tested only.
Theoretical (Hayes et al. 2013; Heffner et al. 2010; Resende et al. 2014) and emerging experimental evidence (Poland et al. 2012; Pryce et al. 2014) shows that, relative to conventional phenotypic selection, GS may increase genetic gain when integrated with existing plant breeding systems. Key factors are shortening the breeding cycle, improving accuracy of selection and accessing within-family variation (Heffner et al. 2010; Resende et al. 2014).

Forages, including PRG, stand to benefit from GS approaches to plant improvement (Hayes et al. 2013), but deployment has been limited by the availability of genomic resources, principally single nucleotide polymorphism (SNP) markers. In recent years, GS has become a realistic option because declining nextgeneration DNA sequencing costs have allowed emergence of open-source, cost-effective SNP marker platforms, such as genotyping-by-sequencing (Elshire et al. 2011).

While enabled by the emerging molecular technologies, GS is dependent on accurate phenotypic data for field performance of large plant populations. Spaced plant performance is a poor predictor of performance of populations in swards (Hayward \& Vivero 1984; Lazenby \& Rogers 1964; Waldron et al. 2008). Half-sibling (HS) families obtained from interpollenating groups of plants in poly-crosses can be used to sow small swards or rows that better represent pasture conditions (Smith et al. 2001), allowing an estimate of yield potential to be captured for the seed parent of the HS family.

A multi-site experiment of a large set of HS families was established to create a training population trait dataset for the development of GS models. The experiment aimed to determine the variation amongst families within populations for forage yield and forage quality parameters, to determine family means and determine whether there is significant variation amongst families to support training of effective GS models for these traits, when associated with high density SNP profiles. Here we describe key insights derived at the halfway stage of what is an on-going experiment. Although our goal is to build a GS model accounting for yield, 
nutritive quality and persistence, this paper focuses primarily on yield.

\section{Materials and Methods}

For each of five PRG breeding populations in the Grasslands Innovation Ltd programme, 100-120 plants verified as infected with endophyte strain AR37 were isolated in respective polycrosses in pollenproof greenhouses and seed was harvested from each plant to give up to 120 maternal HS families. Each population was harvested just prior to seed drop, and a few later-maturing plants in each population were allowed to stand for up to a week longer before harvest. Seed was cleaned to achieve a thousand seed weight of approximately $1.8 \mathrm{~g}$, and then sown in eight trials, at Kerikeri (Northland, data not reported), Ruakura (Waikato), Aorangi (Manawatu), Poukawa (Hawke's Bay) and Lincoln (Canterbury). Waikato, Manawatu and Canterbury are important dairying areas and significant users of PRG seed. They are also historically the regions where many PRG evaluation trials are sited. Two trials were sown at both Ruakura and Aorangi, with one at each site grazed intensively by sheep every 2 weeks through summer. All other trials were grazed when $1500-2500 \mathrm{~kg} \mathrm{DM} / \mathrm{ha}$ were visually estimated to have accumulated. At Lincoln there were also two trials, one irrigated. The focus of the experiments was variation within populations, so within each experiment populations were blocked, and families were randomised in three replicates within these blocks. Each plot was a single $1 \mathrm{~m}$ row sown with $0.2 \mathrm{~g}$ seed, using a cone seeder. Rows were spaced 30 $\mathrm{cm}$ apart and 30 or $50 \mathrm{~cm}$ gaps were left at the end of rows. The trial design was constrained to avoid having plots of the same family in different replicates lying in the same traverse or column.

The trials were regularly noted for herbage bulk
(HB), reflecting yield (Smith et al. 2001), sometimes with associated calibration cuts. The notes were visual assessments recorded by different operators at the different sites, and reflected leaf length and tiller density, but ignored gaps in a row where there were no plants. Dry matter yield (DM) was directly measured on each plot in Waikato, Manawatu and Canterbury by harvesting at least once in spring and autumn from autumn 2014, using shearing handpieces, to a height of $4 \mathrm{~cm}$. Usually the whole plot was cut, but on occasions when accumulated herbage was heavy, smaller quadrats were taken from the centre of the plots. Harvested herbage was held in a cool-room then dried and weighed, or in some instances frozen until drying facilities became available. Plot density was noted two or three times per year, particularly to coincide with DM harvests. Samples were also taken from selected trials for forage quality assessments, but these data are not presented or discussed in this paper.

Data were analysed using the linear mixed models options in GENSTAT, with population as a fixed effect, and family-within-population as a random effect. Thus, the results are taken as applying only to these populations, but the families are taken to represent the variation existing within the populations. For acrosstrial analyses, trial and population were fixed effects. Principal components analysis (PCA) was conducted using GENSTAT on family means for individual harvests and notes made to identify major associative trends among performances for seasons and trials.

\section{Results}

A total of $50 \mathrm{HB}$ notes and $15 \mathrm{DM}$ measurements were completed across all seven trials (Kerikeri excluded). Because of the blocked structure of the trials, there is no test for differences among populations in any one experiment, and no test for interaction between

Table 1 Variances and probabilities for combined analysis of seven to $19 \mathrm{HB}$ notes, five to seven DM yield harvests for different seasons and one density note for each of five trials. $\sigma^{2}$ resid = residual variance; $\sigma^{2}$ fam $/ p o p=$ variance of families within populations; $\sigma^{2}$ trial ${ }^{*}$ fam/pop $=$ interaction variance between trial and family. Prob $t=$ probability of the $t$ statistic for a particular variance. Typical criteria for rejecting a null hypothesis at $5 \%$ or $1 \%$ would be $5.0 \times 10^{-2}$ and $1.0 \times 10^{-2}$ respectively.

\begin{tabular}{|c|c|c|c|c|c|c|}
\hline Trait & Season & $\sigma^{2}$ resid & $\boldsymbol{\sigma}_{\mathrm{fam} / \mathrm{pop}}^{2}$ & $\boldsymbol{\sigma}_{\text {trialxfam/pop }}^{2}$ & Prob $t_{\text {fam/pop }}$ & Prob $t_{\text {trialxfam/pop }}$ \\
\hline \multirow[t]{4}{*}{ HB notes } & spring & 1.641 & 0.02 & nil & $1.96 \times 10^{-6}$ & \\
\hline & summer & 1.110 & 0.098 & 0.095 & $7.75 \times 10^{-13}$ & $1.54 \times 10^{-8}$ \\
\hline & autumn & 3.417 & 0.193 & 0.117 & $4.17 \times 10^{-18}$ & $5.97 \times 10^{-10}$ \\
\hline & winter & 1.654 & 0.031 & 0.003 & $2.60 \times 10^{-5}$ & $3.77 \times 10^{-1}$ \\
\hline \multirow[t]{2}{*}{ DM harvests } & spring & 84.7 & 2.9 & 8.9 & $1.34 \times 10^{-4}$ & $9.01 \times 10^{-15}$ \\
\hline & autumn & 107.8 & 3.2 & 3.2 & $3.81 \times 10^{-7}$ & $7.66 \times 10^{-4}$ \\
\hline Plot density & winter & 0.798 & 0.012 & 0.040 & $3.86 \times 10^{-2}$ & $5.89 \times 10^{-4}$ \\
\hline
\end{tabular}


population and experiment. Variation among families within populations was statistically highly significant $(\mathrm{P}<0.001)$ for almost all HB notes and DM harvests at all trials (data not shown for individual notes or harvests). Coefficients of variation ranged from $7 \%$ to $25 \%$ for individual data sets for HB notes and $19 \%$ to $32 \%$ for DM harvests. Correlations for individual plots between the $\mathrm{HB}$ note data and DM harvests in the same month varied from $\mathrm{R}^{2}=0.31$ to $\mathrm{R}^{2}=0.43$. The amongfamily variances tended to be greater for the autumn than for the spring HB notes in the North Island, but not in Canterbury. For DM, the among-family variances were greater in autumn than in spring in all regions.

Populations varied consistently across trials. Significant interaction between trial and family-withinpopulation in summer and autumn did not obscure significant family effects across trials $\left(\sigma^{2}\right.$ fam/pop, Table 1). There was no interaction with trial for winter or spring HB notes. However, the DM data showed a different pattern, in that while among-family variances were significant across trials, interaction with trial was more significant for spring than for autumn.

Autumn HB data for 2 years were also analysed together for the two Ruakura trials (Table 2) and showed that the dominant effect was families within populations. Interaction with year was significant, but interaction with trial (i.e., with summer management) was only modestly significant and not at all significant in either year examined alone. There was no 3-way interaction between trial, year and family.

PCA highlighted performance in the Waikato trials as the dominant factor in family-trial interaction. Some HB notes at other sites assumed importance when individual notes were all included in a PCA (Figure 1), but significant interaction between family and HB note within a season meant that overall seasonal performance outside of Waikato had no bearing on the first two components when PCA was conducted on trial seasonal means (Fig 2). Manawatu and Hawke's Bay data sometimes aligned with Waikato data, but for other components and seasons with Canterbury data.

Density notes (10 notes from five sites, $1-3$ notes per site) also showed significant among-family variation across trials and notes, with significant interaction with trial (Table 1).

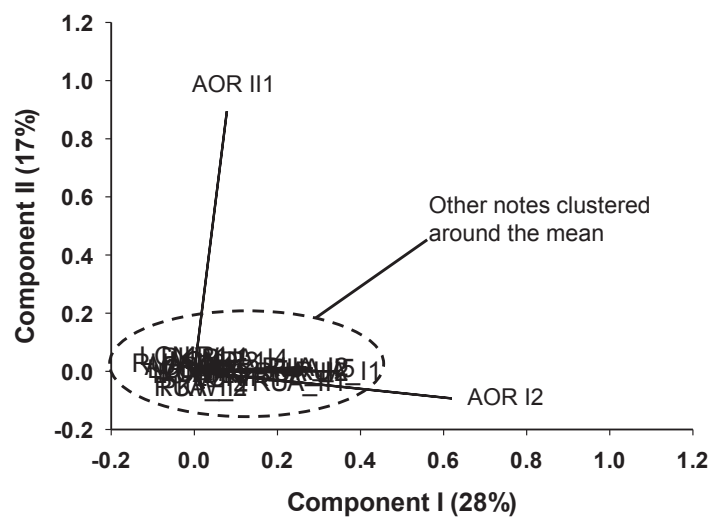

Figure 1 PCA biplot representing 11 individual autumn herbage bulk notes at all sites on the first two components. Note significant alignment of some Manawatu (AOR) notes on these components.

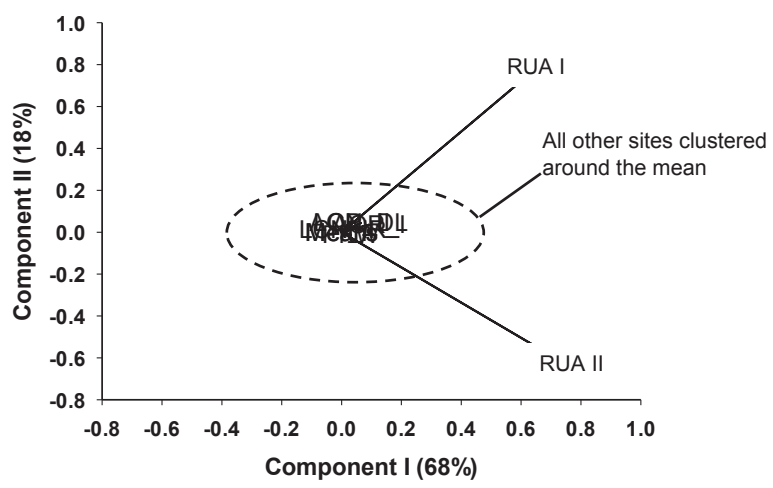

Figure 2 PCA biplot representing site means of autumn herbage bulk notes on the first two components. Note separation of Waikato (RUA) sites for the second component and total lack of alignment of data from any other site.

\section{Discussion}

Yield potential is a cornerstone component of the Forage Value Index (Chapman et al. 2012) and our $\mathrm{DM}$ and $\mathrm{HB}$ note data provide an encouraging basis for development of a genomic selection model enabling its prediction. As a supplement to direct DM measurement, the HB note data consistently correlated with DM from the same season, generally had lower CVs and were more economically captured, enabling a greater

Table 2 Variances and probabilities for combined analysis of autumn herbage bulk notes for the two Ruakura trials. $\sigma^{2}$ resid $=$ residual variance; $\sigma^{2}$ fam $/ p o p=$ variance of families within populations; $\sigma^{2}$ trial ${ }^{\star}$ fam $/ p o p=$ interaction variance between trial and family; $\sigma^{2}$ year ${ }^{*}$ fam $/$ pop = interaction variance between year and family; $\sigma^{2}$ trial ${ }^{*}$ year ${ }^{*}$ fam $/$ pop $=$ interaction variance between trial, year and family. 'Prob t' = probability of the t statistic for a particular variance.

\begin{tabular}{|c|c|c|c|c|c|c|c|}
\hline$\sigma_{\text {resid }}^{2}$ & $\sigma_{\text {fam/pop }}^{2}$ & $\sigma_{\text {trial ×fam/pop }}^{2}$ & $\sigma_{\text {yearxfam/pop }}^{2}$ & $\sigma_{\text {trial×yearxfam/pop }}^{2}$ & $\begin{array}{l}\text { Prob } \\
t_{\text {fam/pop }}\end{array}$ & $\begin{array}{l}\text { Prob } \\
t_{\text {trialxfam }}\end{array}$ & $\begin{array}{l}\text { Prob } \\
\mathrm{t}_{\text {yearxfam }}\end{array}$ \\
\hline 2.065 & 0.535 & 0.098 & 0.149 & nil & $1.09 \times 10^{-17}$ & $1.39 \times 10^{-3}$ & $2.30 \times 10^{-6}$ \\
\hline
\end{tabular}


number of yield estimates per season. CVs were lowest for the irrigated Canterbury trial, but otherwise were similar across all trials, even though a less consistent establishment at some trials might have been expected to lead to their having higher CVs than others.

Genotype-by-environment interaction is a regular feature of perennial ryegrass research results in New Zealand (Easton et al. 2001; Kerr et al. 2012). The statistically significant interaction of site with family does rearrange the ordering of genetic entries (Easton et al. 2001), and this is evident in the current data set. For example, within Population I, of the best ten families ranked on overall autumn performance, only three to seven featured among the best 25 for any one trial. If resulting cultivars are to have broad adaptation, selection within a breeding programme, and phenotyping for the GS model, must use cross-trial means.

The significance across trials of family effects for plant density notes indicates measurable genetic variation for seedling colonisation of the available space and for plant survival. Another 1 or 2 years' data will enable better interpretation.

Typical management of evaluation trials has been found not to predict the persistence challenges suffered by ryegrass pastures (Kerr et al. 2012). Frequent and/or severe summer defoliation is a likely factor in loss of plant vigour in ryegrass pastures (Cosgrove 2011; Reynolds 2013). There was a high among-family variance at the severely-grazed Aorangi trial in April 2015, the first regrowth note after severe grazing every two weeks during summer and early autumn. Unfortunately, the corresponding note from the second Aorangi trial was compromised by severe soil moisture irregularities. Autumn growth notes at both Ruakura trials had high among-family variances in autumn 2014 and again in 2015, with no indication of a differential effect of summer management. Combined analysis of autumn HB notes at the two Ruakura sites showed the dominant effect to be among-family variance across trials (Table 2). However, the two sites did separate on the second multivariate component emerging in the PCA analysis (Fig 2). Evidence for useful variation in tolerance of severe summer grazing is not conclusive at this point. A further one or two year's data may show more clearly whether inclusion of a severe grazing regime is useful in setting up a GS model that incorporates a persistence component.

While Waikato data were the major feature in the PCA, the data did not support the conclusion that other regions could be regarded as a single metaenvironment incorporating the lower North Island and South Island. In some respects Manawatu and Hawke's Bay data were more like those from Waikato than from
Canterbury. Waikato and South Island data provide the major contrast in the economic value of seasonal herbage (Chapman et al. 2012), with the Manawatu situation being intermediate, but for growth data as such other multisite analyses have also found a major contrast between North and South Islands (Easton et al. 2001). Sites in Waikato and Canterbury are a minimum requirement for future trait assessment in ryegrass genomic selection work, but the Manawatu and Hawke's Bay sites provide valuable information on the pattern of variation.

\section{ACKNOWLEDGEMENTS}

The research was funded by Pastoral Genomics, a joint venture co-funded by DairyNZ, Beef+Lamb New Zealand, Dairy Australia, AgResearch Ltd, New Zealand Agriseeds Ltd, Grasslands Innovation Ltd, DEEResearch, and the Ministry of Business, Innovation and Employment (New Zealand). We gratefully acknowledge access to the Grasslands Innovation Ltd breeding pools and thank Alan Stewart, Michael Norriss and Keith Saulsbury of PGG Wrightson Seeds and Tom Lyons of AgResearch for their cooperation. We also gratefully acknowledge the technical input of AgResearch staff Bruce Cooper, Tony Hilditch, Jessica O'Connor, Phil Olyott, Alieu Sartie and many others, and the cooperation of Paul Muir and colleagues of OnFarm Research, Hastings.

\section{REFERENCES}

Brummer, E.C.; Casler, M.D. 2014. Cool-season forages. pp. 33-52. In: Yield gains in major U.S. field crops. Eds. Smith, S.; Diers, B.; Specht, J.; Carver, B. American Society of Agronomy, Inc., Crop Science Society of America, Inc., and Soil Science Society of America, Inc., Madison, WI.

Chapman, D.F.; Bryant, J.R.; McMillan, W.H.; Khaembah, E.N. 2012. Economic values for evaluating pasture plant traits. Proceedings of the New Zealand Grassland Association 74: 209-215.

Cosgrove, G.P. 2011. Long-term trends in production and composition of ryegrass-white clover pasture intensively grazed by dairy-beef cattle. Pasture persistence symposium. Grassland Research \& Practice Series 15: 53-62.

Easton, H.S.; Amyes, J.M.; Cameron, N.E.; Green, R.B.; Kerr, G.A.; Norriss, M.G.; Stewart, A.V. 2002. Pasture plant breeding in New Zealand: Where to from here? Proceedings of the New Zealand Grassland Association 64: 173-179.

Easton, H.S.; Baird, D.B.; Cameron, N.E.; Kerr, G.A.; Norriss, M.; Stewart, A.V. 2001. Perennial ryegrass cultivars: herbage yield in multi-site plot trials. Proceedings of the New Zealand Grassland Association 63: 183-188. 
Elshire, R.J.; Glaubitz, J.C.; Sun, Q.; Poland, J.A.; Kawamoto, K.; Buckler, E.S.; Mitchell, S.E. 2011. A robust, simple Genotyping-by-Sequencing (GBS) approach for high diversity species. PLOS ONE 6: e19379.

Graybosch, R.; Bockelman, H.E.; Garland-Campbell, K.A.; Garvin, D.F.; Regassa, T. 2014. Wheat. pp. 459-488. In: Yield gains in major U.S. field crops. Eds. Smith, S.; Diers, B.; Specht, J.; Carver, B. American Society of Agronomy, Inc., Crop Science Society of America, Inc., and Soil Science Society of America, Inc, Madison, WI.

Hayes, B.J.; Cogan, N.O.I.; Pembleton, L.W.; Goddard, M.E.; Wang, J.; Spangenberg, G.C.; Forster, J.W. 2013. Prospects for genomic selection in forage plant species. Plant Breeding 132: 133-143.

Hayward, M.D.; Vivero, J.L. 1984. Selection for yield in Lolium perenne : II. Performance of spaced plant selections under competitive conditions. Euphytica 33: 787-800.

Heffner, E.L.; Lorenz, A.J.; Jannink, J.-L.; Sorrells, M.E. 2010. Plant breeding with genomic selection: gain per unit time and cost. Crop Science 50: 16811690.

Kerr, G.A.; Chapman, D.F.; Thom, E.R.; Matthew, C.; Linden, A.v.d.; Baird, D.B.; Johnston, E.; Corkran, J.R. 2012. Evaluating perennial ryegrass cultivars: improving testing. Proceedings of the New Zealand Grassland Association 74: 127-136.

Lazenby, A.; Rogers, H.H. 1964. Selection criteria in grass breeding: II. Effect, on Lolium perenne, of differences in population density, variety, and available moisture. Journal of Agricultural Science 62: 285-298.

Poland, J.; Endelman, J.; Dawson, J.; Rutkoski, J.; Wu, S.; Manes, Y.; Dreisigacker, S.; Crossa, J.; Sánchez-Villeda, H.; Sorrells, M.; Jannink, J.-L. 2012. Genomic selection in wheat breeding using genotyping-by-sequencing. The Plant Genome 5: 103-113.
Pryce, J.E.; Gonzalez-Recio, O.; Thornhill, J.B.; Marett, L.C.; Wales, W.J.; Coffey, M.P.; de Haas, Y.; Veerkamp, R.F.; Hayes, B.J. 2014. Validation of genomic breeding value predictions for feed intake and feed efficiency traits. Journal of Dairy Science 97: 537-542.

Resende, R.M.S.; Casler, M.D.; Resende, M.D.V.d. 2014. Genomic selection in forage breeding: accuracy and methods. Crop Science 54: 143-156.

Reynolds, W.N. 2013. Addressing on-farm management to enhance pasture productivity and persistence. Proceedings of the New Zealand Grassland Association 75: 241-244.

Smith, K.F.; Tasneem, M.; Kearney, G.A.; Reed, K.F.M.; Leonforte, A. 2001. Evaluation of herbage yield in a forage grass breeding program: comparison of visual rating versus measurement in single-row plots or swards. Australian Journal of Experimental Agriculture 41: 1161-1166.

Smith, S.; Cooper, M.; Gogerty, J.; Löffler, C.; Borcherding, D.; Wright, K. 2014. Maize. pp. 125172. In: Yield gains in major U.S. field crops. Eds. Smith, S.; Diers, B.; Specht, J.; Carver, B. American Society of Agronomy, Inc., Crop Science Society of America, Inc., and Soil Science Society of America, Inc., Madison, WI.

Waldron, B.L.; Robins, J.G.; Peel, M.D.; Jensen, K.B. 2008. Predicted efficiency of spaced-plant selection to indirectly improve tall fescue sward yield and quality. Crop Science 48: 443-449.

Williams, W.M.; Easton, H.S.; Jones, C.S. 2007. Future options and targets for pasture plant breeding in New Zealand. New Zealand Journal of Agricultural Research 50: 223-248. 
